\title{
Higher dental care is positively associated with key prognosis factors in peritoneal dialysis patients: findings from a retrospective study
}

\author{
Takeyuki Hiramatsu ${ }^{*} \mathbb{0}$, Shota Okumura, Daiki Iguchi and Hiroshi Kojima
}

\begin{abstract}
Background: Oral disease may be increased in people with end-stage renal disease and associated with inflammation, cardiovascular disease, and mortality. Moreover, oral disease may be essential to decide the prognosis of peritoneal dialysis (PD) patients. However, only a few reports have explored the effects of dental care (DC) on cardiovascular diseases and mortality in PD patients. Thus, we aimed to investigate the association of DC with the prognosis of PD patients.
\end{abstract}

Methods: In this single-center, retrospective study, we enrolled 165 incident PD patients aged $\geq 20$ years. We classified patients based on their dental care score, assessed using a self-reported questionnaire into the better dental care group (Group A, score $\geq 7$ ) or the worse dental care group (Group B, score < 7). Demographic, clinical, hospitalization, hospital admission, comorbidities (including congestive heart failure, acute coronary syndrome, stroke, peripheral artery disease, and pneumonia), and mortality (including specific causes) data were extracted from the patient's medical records. Data were analyzed using one-way ANOVA, Wilcoxon t-test, Kruskal-Wallis, Mann-Whitney U-test, chi-square test, Fisher's exact test and multiple regression when appropriate. We compared the survival distributions among groups using the long-rank test.

Results: Of the 165 patients, 75 were allocated to group A and 90 to group B. PD patients with better dental care (group A) had significantly lower levels of C-reactive protein (CRP) and higher levels of serum albumin compared to PD patients with worse dental care (group B). Hospital admissions due to congestive heart failure, acute coronary syndrome, pneumonia, and peritonitis were also lower in group A than group B. Mortality rates due to congestive heart failure, acute coronary syndrome, pneumonia, and sepsis were lower in group A than in group B.

Conclusions: The study highlights the importance of good dental care, particularly for PD patients. Nephrologists and dental professions should design and implement oral health education strategies to improve PD patients' dental care.

Keywords: Peritoneal dialysis, Dental care, Cardiovascular event

*Correspondence: takeyuki@beach.ocn.ne.jp

Department of Nephrology, Aichi Welfare Cooperative Agricultural Federation, Konan-Kosei Hospital, 137 Omatsubara, Takaya-cho,

Konan-City, Aichi 483-8704, Japan

\begin{abstract}
Background
Cardiovascular disease and infection are the most important predictors of survival in patients on dialysis in Japan [1]. In recent decades, it has been found that frequently people with end-stage renal disease (ESRD) have a higher prevalence of oral disease, which may be associated with malnutrition, inflammation, cardiovascular diseases, and mortality [2-6].
\end{abstract} original author(s) and the source, provide a link to the Creative Commons licence, and indicate if changes were made. The images or other third party material in this article are included in the article's Creative Commons licence, unless indicated otherwise in a credit line to the material. If material is not included in the article's Creative Commons licence and your intended use is not permitted by statutory regulation or exceeds the permitted use, you will need to obtain permission directly from the copyright holder. To view a copy of this licence, visit http://creativecommons.org/licenses/by/4.0/. The Creative Commons Public Domain Dedication waiver (http://creativeco mmons.org/publicdomain/zero/1.0/) applies to the data made available in this article, unless otherwise stated in a credit line to the data. 
Poor dental care (DC) is the main factor for developing dental diseases, while good dental hygiene may prevent oral diseases and improve appetite. Thus, a good DC may help maintain a good nutrition state and improve chronic inflammation and malnutrition, as reported previously [2]. Studies have also reported that dental care is associated with severe infections [7, 8], including in peritoneal dialysis (PD) patients [9]. In frail older adults, results from a systematic review showed that good oral health care could reduce aspiration pneumonia incidence [10].

Some studies showed better DC decreased cardiovascular disease $[5,11,12]$. Although oral health hygiene has undeniable importance to PD patient's health, studies exploring the association between DC and the incidence of cardiovascular events, such as congestive heart failure (CHF) or acute coronary syndrome (ACS), are scarce.

In the present study, we aimed to investigate whether DC in PD patients might affect the incidence of cardiovascular diseases and infection, especially peritonitis.

\section{Methods}

\section{Study design and participants}

We conducted this retrospective observational study in the Konan-Kosei Hospital in Japan from January 2010 to December $2019(n=189)$. Patients between the ages of 20 and 80 years were included if they started PD after January 2010. The exclusion criteria were as follows: (1) patients who could not do PD therapy by themselves; and (2) follow-up time less than 3 months after starting PD. Data on 165 incident PD patients who met these criteria and agreed to participate in the present study were extracted from medical records. All patients gave written informed consent. The study protocol was approved by the ethics committee at the Konan-Kosei Hospital and was conducted following the ethical principles stated in the Declaration of Helsinki and the Japanese Ministry of Health, Labor, and Welfare. The reporting of the study follows the STROBE statement and the broader EQUATOR guidelines.

\section{Demographic and clinical data}

Data regarding patient's background, such as age, sex, height, weight, background diseases of ESRD, PD vintage, continuous ambulatory PD (CAPD) or automated PD (APD), serum levels of albumin and C-reactive protein (CRP), Kt/V as total dialysis, and blood pressure were collected once a year at every last visit of the year. Body mass index (BMI) was calculated as weight $(\mathrm{kg})$ divided by height $(\mathrm{m})$ squared. Moreover, biochemical examinations were done once a year at every last visit of the year.

\section{Self-administered DC questionnaire}

After January 2010, we started suggesting DC to all patients on PD. The DC recommendation included brushing teeth three or more times per day, good oral hygiene, outpatient dental visits every 3 months, and prophylactic antibiotics treatment before scaling or caries treatment. Moreover, patients undertook a selfreported questionnaire including the DC performance at the last visit of every year. The DC questionnaire used in this study (Table 1) was a modified version from Japan Dental Association and the questionnaire used in the Oral Diseases in Hemodialysis (ORAL-D) study [13]. The total dental score ranged from zero to thirteen (higher values represented better oral hygiene habits). According to the dental care score, patients were divided into two groups: Group A (better dental health group, score $\geq 7$ ), Group B (low dental health group, score $<7)$.

\section{Hospital admissions, comorbidities, and mortality}

We identified all admissions to the hospital during the study period, excluding those required for dialysis initiation. Each admission was categorized into the following categories: all cases, cases of infectious peritonitis, case of peritonitis with Streptococcus species (sp.), and cases of peritonitis with Staphylococcus $s p$. We also evaluated the incidence of peritonitis, especially due to peritonitis with Streptococcus sp., CHF, ACS, stroke, peripheral artery disease (PAD), and pneumonia.

Further, we collected information on all-cause mortality and the causes of death (allocated into the following categories: CHD, ACS, pneumonia, sepsis, and stroke).

\section{Statistical analysis}

The admission rate was defined as the total incident number/cumulative treatment year. The mortality rate was defined as the incidence divided by cumulative PD patients (/person year). Data were presented as the mean \pm standard deviation for normally distributed variables, while asymmetrically distributed variables were presented as the median and interquartile range. Comparison between the two groups was performed by oneway analysis of variance (ANOVA) testing, followed by an appropriate post hoc analysis including Wilcoxon t-test, Kruskal-Wallis, Mann-Whitney U-test, chi-square test and Fisher's exact test. A multiple regression analysis was used to test the factors related to hospitalization risk in all patients. A $p<0.05$ was considered to be statistically significant. Statistical analyses were performed using SPSS version 23 statistical software for Windows (SPSS, Inc., Chicago, IL, USA). 
Table 1 Dental care questionnaire (modified from ORAL-D study questionnaire)

\begin{tabular}{|c|c|c|}
\hline Question & Score & Description \\
\hline \multirow[t]{4}{*}{ How many times in a day do you brush your teeth? } & 0 & Less than one \\
\hline & 1 & One \\
\hline & 2 & Two \\
\hline & 3 & Three or more \\
\hline \multirow[t]{3}{*}{ Do you use dental floss? } & 0 & No \\
\hline & 1 & Sometimes \\
\hline & 2 & Every day \\
\hline \multirow[t]{3}{*}{ Do you use mouse wash? } & 0 & No \\
\hline & 1 & Sometimes \\
\hline & 2 & Every day \\
\hline \multirow[t]{2}{*}{ How many teeth do you have? } & 0 & Less than 20 \\
\hline & 1 & 20 and more \\
\hline \multirow[t]{4}{*}{ When did you make the latest dental visit? } & 0 & Do not remember \\
\hline & 1 & Over 1 year ago \\
\hline & 2 & Less than 1 year ago \\
\hline & 3 & Less than 6 months ago \\
\hline \multirow[t]{4}{*}{ How often do you change your toothbrush? } & 0 & Less than 2 times per year \\
\hline & 1 & Every 6 months \\
\hline & 2 & Every 3 months \\
\hline & 3 & Every 1 month \\
\hline \multirow[t]{2}{*}{ Do you use prophylactic antibiotics before a dental procedure? } & 0 & No \\
\hline & 1 & Yes \\
\hline
\end{tabular}

\section{Results}

\section{Patient groups and characteristics}

According to the inclusion and exclusion criteria, from the eligible 189 patients, 24 patients were excluded (22 were unable to do the PD by themselves, and two were moved to other clinics). Thus, 165 patients were retrieved from the medical record and split into two groups based on their dental care score. The patient's dental scores ranged between 0 and 13, the average score was $6.93 \pm 1.33$, and the median value was 7. Therefore, patients' data were divided into two groups: Group A (dental care score $\geq 7 ; n=268$ ) and Group B (dental care score $<7 ; n=302$ ). Mean observational period was $58.9 \pm 40.0$ months in Group A and $49.8 \pm 32.8$ months in Group B $(p=0.001)$.

Both groups had similar characteristics, as the only significant differences were observed in serum levels of CRP (known to correlate with the magnitude of the inflammatory response), serum albumin, and BMI. Patients in group A had significantly lower CRP levels and significantly higher serum albumin and BMI (reflecting the nutritional status or inflammatory state of the whole body) compared with patients in group B (Table 2).

Our data showed a significant correlation between dental care score (DCS) with both serum CRP levels $(r=-0.401, p=0.001)$ and albumin levels $(r=0.367$, $p=0.001)$.

\section{Comparison of patients' hospitalization and admission rates by cause-specific between oral hygiene levels}

Overall, the frequency of hospitalization and the admission rate due to all complications were significantly higher in group B patients than in group A (Fig. 1). From all the recorded complications that lead to hospital admission, CHF and ACS were the two conditions with a particularly high incidence in patients from group B compared with group A. Only hospital admission rates due to stroke and PAD was similar between the two groups. Similar results are depicted in Fig. 2, comparing the time distribution until the event of interest in the two independent groups using the log-rank test.

In summary, prevalence rates for all complications, except for stroke (Fig. 2c) and PAD (data not shown), were significantly higher in group $B$ than in group A (Fig. 2a, b, d, e, f). Thus, compared with PD patients with better dental care (group A), the peritonitis-free period was significantly shorter in PD patients with worse dental care group B. Participants in Group B had lower toothbrushing frequency than those in Group A $(1.33 \pm 0.58$ vs. $2.54 \pm 0.50(p=0.001)$. Moreover, the multiple regression analysis (Table 3 ) revealed that toothbrushing frequency 
Table 2 Patient characteristics

\begin{tabular}{|c|c|c|c|}
\hline & $\begin{array}{l}\text { Group A } \\
(n=75)\end{array}$ & $\begin{array}{l}\text { Group B } \\
(n=90)\end{array}$ & $p$ value \\
\hline Dental care score & $9.2 \pm 1.2$ & $4.0 \pm 1.1$ & $0.001^{* *}$ \\
\hline Age (year) & $63.9 \pm 12.0$ & $64.2 \pm 10.5$ & 0.875 \\
\hline Male sex, n (\%) & $42(56.0)$ & $53(58.9)$ & 0.829 \\
\hline PD vintage (month) & $58.9 \pm 40.0$ & $49.8 \pm 32.8$ & $0.001^{* *}$ \\
\hline Type of PD & & & 0.715 \\
\hline CAPD, $n(\%)$ & $29(38.6)$ & $36(40.0)$ & \\
\hline APD, $n(\%)$ & $49(61.4)$ & $54(60.0)$ & \\
\hline Kidney disease due to ESRD & & & 0.892 \\
\hline CGN, $n(\%)$ & $34(45.3)$ & $42(46.7)$ & \\
\hline $\mathrm{DM}, n(\%)$ & $15(20.0)$ & $18(20.0)$ & \\
\hline $\mathrm{NS}, n(\%)$ & $21(28.0)$ & $24(26.7)$ & \\
\hline Other CKDs, $n(\%)$ & $5(6.7)$ & $6(6.7)$ & \\
\hline BMI $\left(\mathrm{kg} / \mathrm{m}^{2}\right)$ & $23.5 \pm 3.2$ & $22.7 \pm 2.3$ & $0.048^{*}$ \\
\hline Smoking status & & & 0.848 \\
\hline Never, $n(\%)$ & $44(58.7)$ & $54(60.0)$ & \\
\hline Past, $n(\%)$ & $25(33.3)$ & $27(30.0)$ & \\
\hline Current, $n(\%)$ & $6(8.0)$ & $9(10.0)$ & \\
\hline CRP $(\mathrm{mg} / \mathrm{dL})$ & $0.19 \pm 0.04$ & $0.21 \pm 0.05$ & $0.045^{*}$ \\
\hline Albumin (g/dL) & $3.41 \pm 0.15$ & $3.23 \pm 0.20$ & $0.001^{* *}$ \\
\hline LDL-cholesterol (mg/dL) & $108.2 \pm 23.9$ & $110.2 \pm 31.5$ & 0.738 \\
\hline HDL-cholesterol (mg/dL) & $50.3 \pm 9.4$ & $49.8 \pm 10.9$ & 0.556 \\
\hline $\mathrm{SBP}(\mathrm{mmHg})$ & $150.4 \pm 11.6$ & $151.1 \pm 14.2$ & 0.653 \\
\hline $\mathrm{DBP}(\mathrm{mmHg})$ & $85.2 \pm 4.2$ & $86.2 \pm 5.1$ & 0.140 \\
\hline $\mathrm{Kt} / \mathrm{N}$ & $1.88 \pm 0.25$ & $1.83 \pm 0.30$ & 0.071 \\
\hline
\end{tabular}

Data are expressed as mean \pm standard deviation

$A P D$ automated peritoneal dialysis, BMI body mass index, CAPD continuous ambulatory peritoneal dialysis, CGN chronic glomerulonephritis, CRP C-reactive protein, DBP diastolic blood pressure, DM diabetes mellitus, NS nephrosclerosis, $P D$ peritoneal dialysis, SBP systolic blood pressure

${ }^{*} p<0.05 ;{ }^{* *} p<0.001$

was the most important factor for all-cause peritonitis ( $t$ value $=-2.182, p=0.048)$, Streptococcal peritonitis $(t$ value $=-2.739, p=0.006)$, CHF $(t$ value $=-1.739$, $p=0.059)$ and pneumonia ( $t$ value $=-2.916, p=0.004)$ for all participants. Also, dental visit was another main factor associated with CHF $(t$ value $=-2.463, p=0.014$ ) and with ACS ( $t$ value $=-2.094, p=-0.037)$.

We also evaluated the hospitalization for all participants according to the changes in DCS compared with that of the baseline by dividing PD patients into three groups (decreased $[n=26]$, no change $[n=73]$, increased $[n=18])$. The admission rates were higher in decreased DCS groups, on the other hand, lower in the increased DCS groups except for stroke or PAD (Table 4). Moreover, we found that the distribution of the patients by DCS group differed based on the following characteristics: all peritonitis $\left(\chi^{2}=8.54, p=0.013\right)$, Streptococcal peritonitis $\left(\chi^{2}=11.89, p=0.003\right), \mathrm{CHF}\left(\chi^{2}=8.80, p=0.012\right)$, and ACS $\left(\chi^{2}=10.12, p=0.006\right)$ No association was found between DCS group and the remaining characteristics (pneumonia, infection, stroke, and PAD). Moreover, Fisher's exact analysis was used to compare the risk of respective hospitalization between decreased and increased group. The findings revealed hospitalization in decreased group had a higher risk in all peritonitis $(p=0.006)$, Streptococcus $(p=0.001)$, CHF $(p=0.013)$, and ACS $(p=0.041)$ than those in increased group, but in Staphylococcus $(p=0.536)$, stroke $(p=0.151)$, PAD $(p=0.133)$, pneumonia $(p=0.439)$, or other infection $(p=0.682)$, there were no relationship between the two groups.

\section{Mortality rates in PD by oral hygiene level}

All-cause mortality rates were significantly higher in PD patients with worse dental care (group B) than in patients with better dental care (group A; $p=0.001$ ). In the stratified analysis by cause of death (Fig. 3), PD patients in group $\mathrm{B}$ also had significantly higher mortality due to CHF, ACS, pneumonia, and sepsis than PD patients in group A. Only the mortality rates due to stroke were similar among the two groups $(p=0.805)$. None of the patients died from peritonitis. Moreover, patients who died from sepsis had no evidence of pneumonia or other infectious focuses, except for bacteremia on admission. Multiple regression analysis showed that dental visit frequency was the major factor in mortality due to CHF ( $t$ value $=-1.993, p=0.050)$ and ACS ( $t$ value $=-1.883$ $p=0.062$ ) (other data not shown). The survival curves using log-rank analysis (Fig. 4) showed similar results, indicating that worse oral hygiene was significantly associated with decreased survival rate in patients with $\mathrm{CHF}$, ACS, and pneumonia. Our findings revealed that dental health might improve the survival rate in sepsis, but without significance. Nevertheless, there was no effect on the survival rate of stroke patients (Fig. 4a, b, d, e, f).

\section{Discussion}

This study showed that serum albumin values were significantly higher, and CRP values were significantly lower among the patients with better DC services. Notably, CRP and serum albumin levels were correlated with DC scores. That is to say, better dental care health might induce a higher value of serum albumin and a lower value of CRP. These findings suggest that dental hygiene may improve chronic inflammation and nutritional state in PD patients. In addition, we found that dental hygiene is associated with reduced admission rates due to peritonitis, pneumonia, cardiovascular events and is also associated with mortality due to cardiovascular events.

In previous reports, dental diseases were shown to be associated with a higher risk of malnutrition, inflammation, and cardiovascular events in ESRD patients [5], with possible positive implications in other frequent 


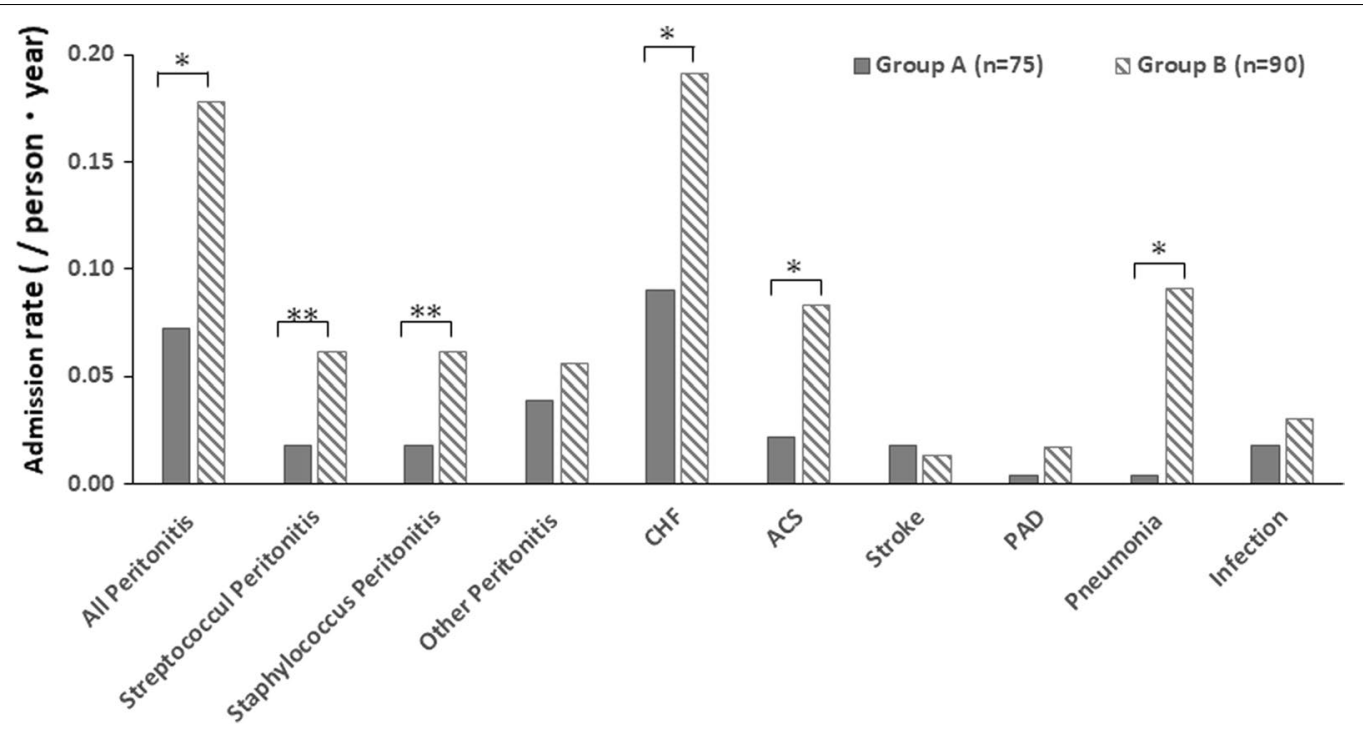

Fig. 1 Comparison of hospital admission rates by cause-specific admission between Group A and B. According to all hospitalization, acute coronary syndrome, congestive heart failure, peritonitis (all, Streptococcus or Staphylococcus related), and pneumonia, admission rates were significantly lower in group A than B. Nevertheless, the admission rate due to stroke and PAD were similar between groups A and B. ${ }^{*} p<0.01 ;{ }^{* *} p<0.05$

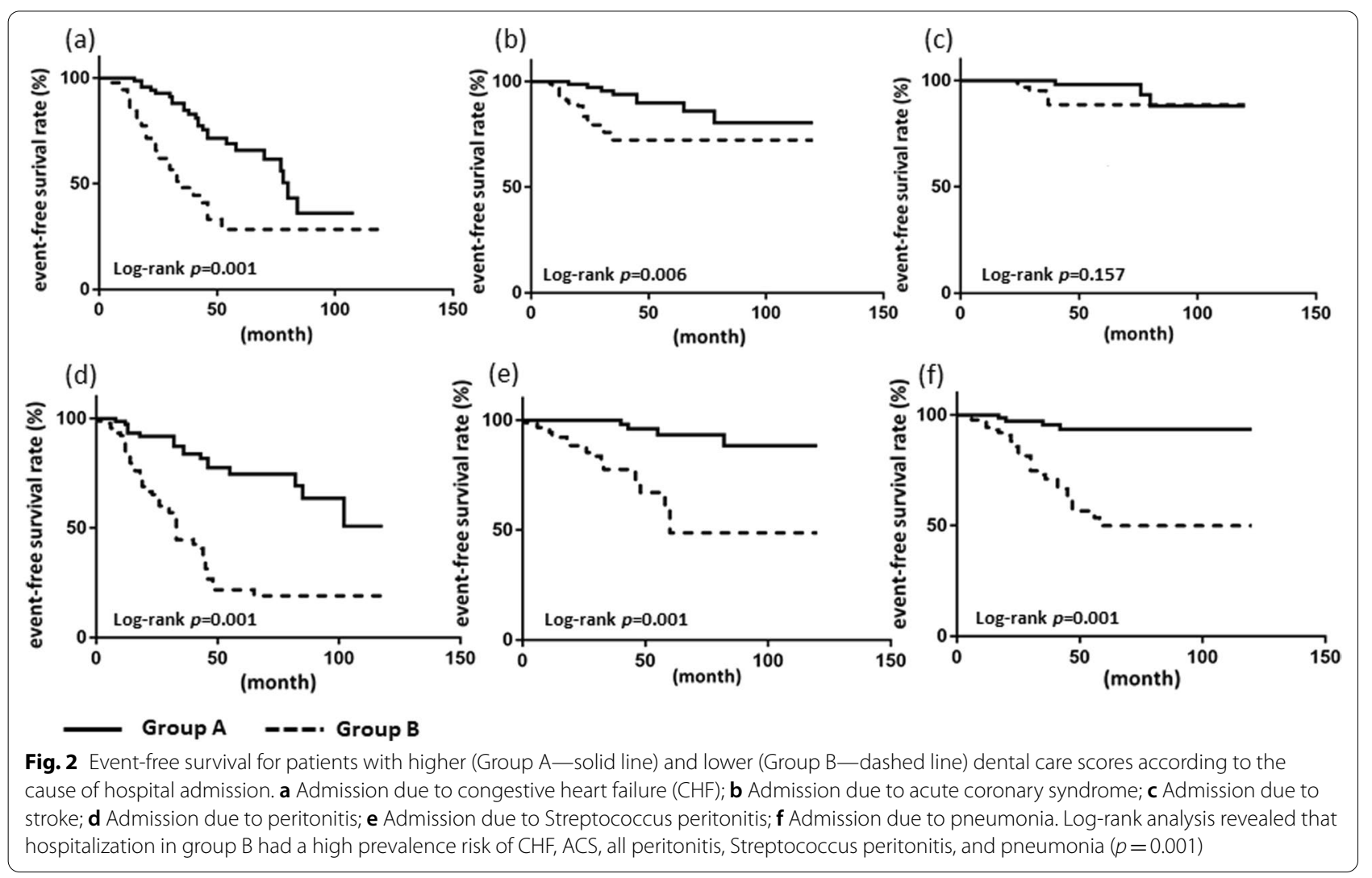


Table 3 Multiple regression analysis of risk factors related to hospitalization risk in all patients

\begin{tabular}{|c|c|c|c|}
\hline Question & Complication & $t$ value & $p$ value \\
\hline \multirow[t]{9}{*}{ How many times in a day do you brush your teeth? } & All peritonitis & -2.182 & $0.048^{*}$ \\
\hline & Streptococcal peritonitis & -2.739 & $0.006^{* *}$ \\
\hline & Staphylococcal peritonitis & -1.787 & 0.075 \\
\hline & $\mathrm{CHF}$ & -1.739 & 0.056 \\
\hline & ACS & -1.332 & 0.183 \\
\hline & Stroke & 0.731 & 0.465 \\
\hline & PAD & 0.324 & 0.746 \\
\hline & Pneumonia & -2.916 & $0.004^{* *}$ \\
\hline & Other infection & -0.143 & 0.886 \\
\hline \multirow[t]{9}{*}{ Do you use dental floss? } & All peritonitis & 0.368 & 0.713 \\
\hline & Streptococcal peritonitis & 1.018 & 0.309 \\
\hline & Staphylococcal peritonitis & -0.013 & 0.989 \\
\hline & $\mathrm{CHF}$ & 1.518 & 0.098 \\
\hline & ACS & -1.608 & 0.106 \\
\hline & Stroke & 0.694 & 0.488 \\
\hline & PAD & -0.875 & 0.382 \\
\hline & Pneumonia & 1.016 & 0.310 \\
\hline & Other infection & 0.266 & 0.791 \\
\hline \multirow[t]{9}{*}{ Do you use mouse wash? } & All peritonitis & 0.577 & 0.564 \\
\hline & Streptococcal peritonitis & 2.050 & $0.041^{*}$ \\
\hline & Staphylococcal peritonitis & -0.321 & 0.749 \\
\hline & $\mathrm{CHF}$ & 0.051 & 0.959 \\
\hline & ACS & -0.373 & 0.709 \\
\hline & Stroke & -0.337 & 0.736 \\
\hline & PAD & -0.176 & 0.860 \\
\hline & Pneumonia & -0.617 & 0.537 \\
\hline & Other infection & -0.681 & 0.496 \\
\hline \multirow[t]{9}{*}{ How many teeth do you have? } & All peritonitis & 1.635 & 0.103 \\
\hline & Streptococcal peritonitis & 0.458 & 0.647 \\
\hline & Staphylococcal peritonitis & 1.686 & 0.098 \\
\hline & $\mathrm{CHF}$ & 0.585 & 0.559 \\
\hline & ACS & 1.448 & 0.148 \\
\hline & Stroke & 1.220 & 0.102 \\
\hline & PAD & -0.975 & 0.330 \\
\hline & Pneumonia & -1.810 & 0.071 \\
\hline & Other infection & 0.283 & 0.777 \\
\hline \multirow[t]{9}{*}{ When did you make the latest dental visit? } & All peritonitis & -1.525 & 0.132 \\
\hline & Streptococcal peritonitis & -0.502 & 0.616 \\
\hline & Staphylococcal peritonitis & -1.891 & 0.059 \\
\hline & $\mathrm{CHF}$ & -2.463 & $0.014^{*}$ \\
\hline & ACS & -2.094 & $0.037^{*}$ \\
\hline & Stroke & 0.038 & 0.970 \\
\hline & PAD & 0.200 & 0.842 \\
\hline & Pneumonia & -1.368 & 0.172 \\
\hline & Other infection & -1.110 & 0.268 \\
\hline
\end{tabular}


Table 3 (continued)

\begin{tabular}{|c|c|c|c|}
\hline Question & Complication & $t$ value & $p$ value \\
\hline \multirow[t]{9}{*}{ How often do you change your toothbrush? } & All peritonitis & -1.568 & 0.118 \\
\hline & Streptococcal peritonitis & -2.895 & $0.004^{* *}$ \\
\hline & Staphylococcal peritonitis & -1.697 & 0.090 \\
\hline & $\mathrm{CHF}$ & 1.895 & $0.044^{*}$ \\
\hline & ACS & -2.203 & $0.028^{*}$ \\
\hline & Stroke & -1.000 & 0.318 \\
\hline & $\mathrm{PAD}$ & 1.239 & 0.216 \\
\hline & Pneumonia & -0.754 & 0.451 \\
\hline & Other infection & -1.515 & 0.130 \\
\hline \multirow[t]{9}{*}{ Do you use prophylactic antibiotics before a dental procedure? } & All peritonitis & -0.753 & 0.452 \\
\hline & Streptococcal peritonitis & -0.394 & 0.694 \\
\hline & Staphylococcal peritonitis & 1.061 & 0.289 \\
\hline & $\mathrm{CHF}$ & -1.935 & $0.048^{*}$ \\
\hline & ACS & -0.721 & 0.472 \\
\hline & Stroke & -1.727 & 0.085 \\
\hline & PAD & -0.894 & 0.372 \\
\hline & Pneumonia & -0.381 & 0.703 \\
\hline & Other infection & -1.065 & 0.288 \\
\hline
\end{tabular}

ACS acute coronary syndrome, $C H F$ congestive heart failure

${ }^{*} p<0.05 ;{ }^{* *} p<0.001$

Table 4 Comparison of hospital admission rates according to DCS change in all patients

\begin{tabular}{|c|c|c|c|c|c|}
\hline \multirow[t]{2}{*}{ Cause of hospitalization } & \multicolumn{5}{|l|}{ DCS } \\
\hline & Decreased $(n=26)$ & No change $(n=73)$ & Increased $(n=18)$ & $x^{2}$ value & $p$ value \\
\hline All peritonitis [ $n(\%)]$ & $20(76.9)$ & $39(53.4)$ & $6(33.3)$ & 8.54 & $0.013^{*}$ \\
\hline Streptococcal peritonitis [n (\%)] & $11(42.3)$ & $14(19.2)$ & $0(0.0)$ & 11.89 & $0.003^{* *}$ \\
\hline Staphylococcal peritonitis [n (\%)] & $8(30.8)$ & $24(32.9)$ & $4(22.2)$ & 0.79 & 0.676 \\
\hline $\operatorname{ACS}[n(\%)]$ & $14(53.8)$ & $39(53.4)$ & $3(16.7)$ & 8.80 & $0.012^{*}$ \\
\hline CHF $[n(\%)]$ & $8(30.8)$ & $19(26.0)$ & $1(5.6)$ & 10.21 & $0.006^{* *}$ \\
\hline Stroke $[n(\%)]$ & $4(15.4)$ & $7(9.6)$ & $6(33.3)$ & 5.31 & 0.070 \\
\hline $\operatorname{PAD}[n(\%)]$ & $4(15.4)$ & $5(6.8)$ & $0(0.0)$ & 4.22 & 0.121 \\
\hline Pneumonia [n (\%)] & $6(23.1)$ & $19(26.0)$ & $2(11.1)$ & 1.98 & 0.372 \\
\hline Other infection [n (\%)] & $5(19.3)$ & $8(11.0)$ & $2(11.1)$ & 1.06 & 0.588 \\
\hline
\end{tabular}

ACS acute coronary syndrome, $C H F$ congestive heart failure, $P A D$ peripheral artery disease

${ }^{*} p<0.05 ;{ }^{* *} p<0.001$

health issues, such as frailty or sarcopenia. In line with another previous report [3], our results support that dental hygiene could improve chronic inflammation and malnutrition. In addition, our finding showed that regular toothbrushing and prophylactic antibiotics treatment might reduce the microorganism in the oral cavity, followed by a reduced risk of peritonitis or pneumonia. Moreover, several dental visits might improve oral health, reducing the risk of CHF or ACS.
To improve the prognosis and quality of life of PD patients, it is imperative to reduce the incidence of peritonitis, pneumonia, CHF, and ACS. Although preventing these complications is challenging and complex, our study may suggest that maintaining good oral hygiene and care could help prevent infectious diseases, including peritonitis and pneumonia, and some cardiovascular diseases, such as CHF and ACS. The mechanisms explaining this effect may reduce chronic inflammation 


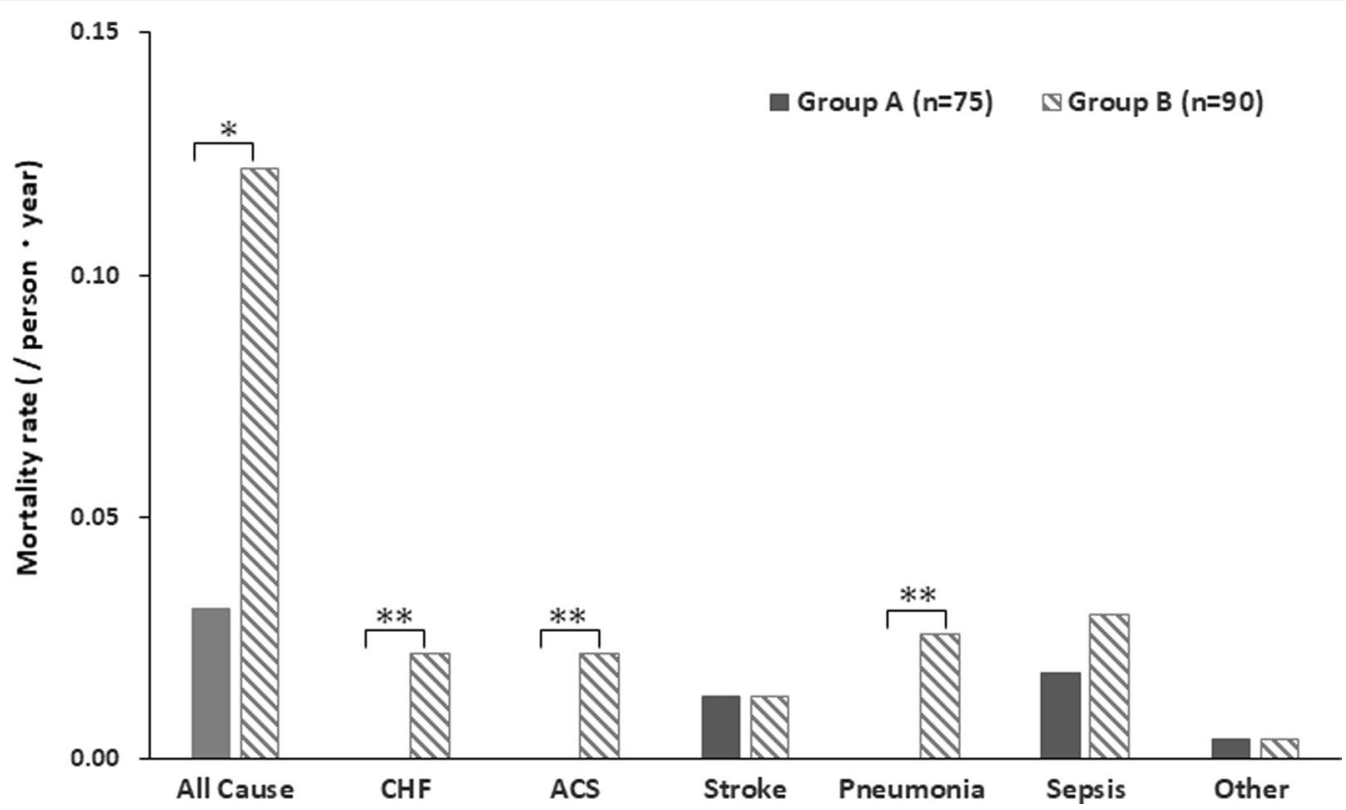

Fig. 3 All-cause and cause-specific mortality rates in PD patients with higher and lower dental care score. ${ }^{*} p<0.01 ;{ }^{* *} p<0.05$

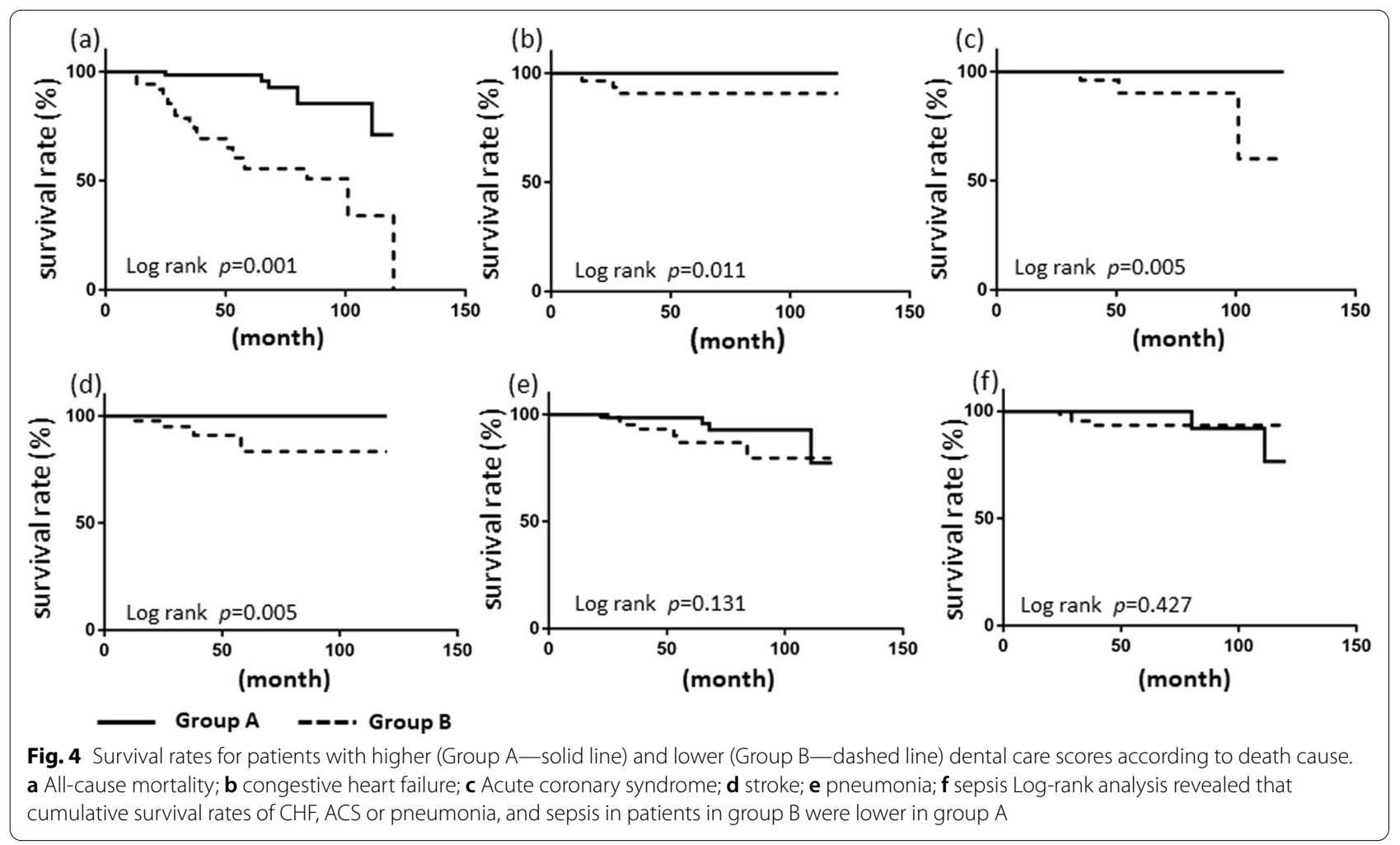

and malnutrition, as supported by other findings. Also, gingival inflammation might play an essential role in the pathogenesis of atherosclerosis and represent a higher risk for cardiovascular disease [13-15]. It was reported that accumulated dental plaque drove neutrophil-based inflammation and metastatic immunologic response to oral microorganisms [16] and that subgingival biofilm in periodontal pockets enabled translocation of oral 
bacteria into the circulation system [17]. In hemodialysis patients, periodontitis was also associated with increased malnutrition and systemic inflammation [18]. Frequent dental visits and frequent change of toothbrush might maintain a better oral health condition, such as reducing dental plaque, which might reduce the risk of CHF or ACS, as our results showed.

Previous studies have described some of the adverse outcomes in chronic kidney disease patients that might be caused due to poor oral care, including endothelial dysfunction [19], atherosclerosis [20], thrombosis [21], vascular injury, and endotoxemia [22]. Septicemia may induce bacterial translocation from subgingival biofilm, and poor dental health may also injure the immune response during sepsis $[13,22]$. Then, better dental care may reduce the risk of cardiovascular events and reduce the hospitalization of PD patients [23].

Peritonitis is a leading factor associated with the withdrawal of PD in our region, in Japan [23], and globally $[24,25]$. However, our findings showed that peritonitis was not a cause of death in the study population, suggesting that DC could have lowered peritonitis incidence. Educating patients in improving their oral hygiene will likely be beneficial for preventing systematic diseases, including cardiovascular disease.

Oral disease is a common complication in adults with chronic kidney disease [14]. Simple strategies to improve oral health include increasing the frequency of brushing and dental visits. Frequent brushing and removal of tartar prevent subgingival bacterial biofilm formation in periodontal pockets [15], which may decrease the risk of cardiovascular events. Moreover, regular teeth brushing might reduce Streptococcal peritonitis incidence by preventing bacterial translocation into the circulation system. Our findings revealed that sepsis (due to Streptococcal peritonitis) was associated with an increased mortality rate in PD patients with poor DC (group B).

This study had some limitations. First, it is a retrospective observational single-center study. Thus, a multicenter, double-blind prospective study would be recommended based on the evidence in this study. Second, all patients in the study had already received dental care recommendations, such as frequent brushing, careful oral hygiene, regular dental visits, and prophylactic antibiotics treatment before scaling or caries treatment. Thus, the patients with poor DC (group B) do not represent the typical level of oral hygiene in PD patients. Third, aside from hospitalization cases, many outpatients have similar complications, but those cases were not evaluated. Finally, we used a self-reported questionnaire to determine the DC level.

\section{Conclusions}

Our study revealed that DC is beneficial not only for hospitalization cases due to cardiovascular disease (including CHF or ACS) but also in cases of peritonitis, especially Streptococcal peritonitis. Given the importance of DC in improving quality of life and treatment survival, it is vital to encourage and educate PD patients to improve their oral health. Although successful educational or intervention strategies can be implemented to improve oral hygiene, those would greatly benefit from the cooperation between the nephrologists and dental professionals.

\section{Abbreviations \\ ACS: Acute coronary syndrome; ANOVA: Analysis of variance; APD: Automated peritoneal dialysis; BMI: Body mass index; CAPD: Continuous ambulatory peritoneal dialysis; CHF: Congestive heart failure; CRP: C-reactive protein; DC: Dental care; ESRD: End-stage renal disease; PAD: Peripheral artery disease; PD: Peritoneal dialysis.}

\section{Acknowledgements}

We thank patients and staff and acknowledge the input of many other members of the team who assisted in performing the study.

\section{Authors' contributions}

All authors discussed the study protocol and participated in data collection. Data analysis was done by TH and HK. After that, the study findings were discussed by all authors. TH wrote the manuscript draft. All authors approved the final manuscript version.

\section{Funding}

This study was not supported by any grant or sponsor.

\section{Availability of data and materials}

The datasets used and/or analyzed during the present study are available from the corresponding author upon reasonable request.

\section{Declarations}

\section{Ethics approval and consent to participate}

The Ethics Committee of the Konan-Kosei Hospital approved this study (Konan-Kosei Rinsho Kenkyu 2020-036(0403)Ver2.0), and it was conducted following the ethical principles of the Declaration of Helsinki.

\section{Consent for publication}

Not applicable.

\section{Competing interests}

The authors declare that they have no competing interests.

Received: 12 February 2021 Accepted: 3 December 2021

Published online: 02 March 2022

\section{References}

1. Masakane I, Taniguchi M, Nakai S, et al. Annual dialysis data report 2016, JSDT Renal Data Registry. Ren Replace Ther. 2018:4:45.

2. Persson GR, Persson RE. Cardiovascular disease and periodontitis: an update on the associations and risk. J Clin Periodontol. 2008;35(Suppl 8):362-79.

3. de Oliveira C, Watt R, Hamer M. Toothbrushing, inflammation, and risk of cardiovascular disease: results from Scottish Health Survey. BMJ. 2010;340:c2451. 
4. Strippoli GFM, Palmer SC, Ruospo M, et al. Oral disease in adults treated with hemodialysis: prevalence, predictors, and association with mortality and adverse cardiovascular events: the rationale and design of the ORAL Diseases in hemodialysis (ORAL-D) study, a prospective, multinational, longitudinal, observational, cohort study. BMC Nephrol. 2013;14:90.

5. Park SY, Kim SH, Kang SH, et al. Improved oral hygiene care attenuates the cardiovascular risk of oral health disease: a population-based study from Korea. Eur Heart J. 2019;40:1138-45.

6. Kossioni AE. The association of poor oral health parameters with malnutrition in older adults: a review considering the potential implications for cognitive impairment. Nutrients. 2018;10:1709.

7. Weise H, Naros A, Weise C, Reinert S, Hoefert S. Severe odontogenic infection with septic progress- a constant and increasing challenge: a retrospective analysis. BMC Oral Health. 2019;19:173.

8. Sánchez R, Mirada E, Arias J, Paño JR, Burgueño M. Severe odontogenic infections: epidemiological, microbiological and therapeutic factors. Med Oral Patol Oral Cir Bucal. 2011;16:e670-6.

9. Oka H, Yamada S, Kamimura T, et al. Better oral hygiene habits are associated with a lower incidence of peritoneal dialysis-related peritonitis. Ther Apher Dial. 2019;23:187-94.

10. van der Maarel-Wierink CD, Vanobbergen JN, Bronkhorst EM, Schols $J M$, de Baat C. Oral health care and aspiration pneumonia in frail older people: a systematic literature review. Gerodontology. 2013;30:3-9.

11. Chang Y, Woo HG, Park J, Lee JS, Song TJ. Improved oral hygiene care is associated with decreased risk of occurrence for atrial fibrillation and heart failure: a nationwide population-based cohort study. Eur J Prev Cardiol. 2020;27(17):1835-45.

12. Tavares M, Calabi KAL, Martin LS. Systemic diseases and oral health. Dent Clin N Am. 2014;58:797-814.

13. Stippoli GF, Palmer SC, Ruospo M, et al. Oral disease in adults treated with hemodialysis: prevalence, predictors, and association with mortality and adverse cardiovascular events: the rationale and design of the ORAL diseases in hemodialysis (ORAL-D) study, a prospective, multinationale longitudinal, observation, cohort study. BMC Nephrol. 2013;14:90.

14. Grubbs V, Plantinga LC, Tuot DS, Powe NR. Chronic kidney disease and use of dental services in a United States Public Healthcare System: a retrospective cohort study. BMC Nephrol. 2012;13:16.

15. Ruospo M, Palmer SC, Craig JC, et al. Prevalence and severity of oral disease in adults with chronic kidney disease: a systematic review of observational studies. Nephrol Dial Transplant. 2014;29:364-75.

16. Thoden van Velzen SK, Abraham-Inpijn L, Moorer WR. Plaque and systemic disease: a reappraisal of the focal infection concept. J Clin Periodontol. 1984;11:209-20.

17. Chang Y, Woo HG, Park J, Lee JS, Song TJ. Improved oral hygiene care is associated with decreased risk of occurrence for atrial fibrillation and heart failure: a nationwide population-based cohort study. Eur J Prev Cardiol. 2020;27:1835-45.

18. Li-Ping C, Chiang C, Chan C, Hung KY, Huang CS. Does periodontitis reflect inflammation and malnutrition status in hemodialysis patients? Am J Kidney Dis. 2016;47:815-22.

19. Seinost G, Wimmer G, Skerget M, et al. Periodontal treatment improves endothelial dysfunction in patients with severe periodontitis. Am Heart J. 2005;149:1050-4.

20. Fisher MA, Borgnakke WS, Taylor GW. Periodontal disease as a risk marker in coronary heart disease and chronic kidney disease. Curr Opin Nephrol Hypertens. 2010;19:519-26.

21. Kowolik MJ, Dowsett SA, Rodriquez J, De La Rosa RM, Eckert GJ. Systemic neutrophil response resulting from dental plaque accumulation. J Periodontol. 2001;72:146-51.

22. Geerts SO, Nys M, De MP, et al. Systemic release of endotoxins induced by gentle mastication: association with periodontitis severity. J Periodontol. 2002;73:73-8

23. Mizuno M, Ito Y, Suzuki Y, et al. Recent analysis of status and outcomes of peritoneal dialysis in the Tokai area of Japan: the second report of the Tokai peritoneal dialysis registry. Clin Exp Nephrol. 2016;20:960-71.

24. Mehrotra R, Devuyst O, Davies SJ, Johnson DW. The current state of peritoneal dialysis. J Am Soc Nephrol. 2016;27:3238-52.

25. Béchade C, Guittet L, Evans D, Verger C, Ryckelynck JP, Lobbedez T. Early failure in patients starting peritoneal dialysis: a competing risks approach. Nephrol Dial Transplant. 2014;29:2127-35.

\section{Publisher's Note}

Springer Nature remains neutral with regard to jurisdictional claims in published maps and institutional affiliations.
Ready to submit your research? Choose BMC and benefit from:

- fast, convenient online submission

- thorough peer review by experienced researchers in your field

- rapid publication on acceptance

- support for research data, including large and complex data types

- gold Open Access which fosters wider collaboration and increased citations

- maximum visibility for your research: over 100M website views per year

At BMC, research is always in progress.

Learn more biomedcentral.com/submissions 